A alma generosa não se divorciou, entretanto, do espirito firme, por vezes vigoroso até, mas que agia sempre com uma sinceridade a toda prova.

Certa vez, pedindo-lhe que em face de certa perogrativa, agisse com complacencia, respondeu-nos elle que até com os proprios filhos, que extremecia, era intransigente, dessa intransigencia que só é dictada pela exacta comprehensão das suas obrigações.

Foi, em summa, um homem justo, recto e cuja lembrança perdurará na mente dos que foram seus amigos e seus alumnos.

A Faculdade de Medicina, perdeu, com elle, um de seus melhores e tnais esforçados professores. A Microbiologia nacional, um dos seus investigadores mais pertinazes e dos seus conhecedores mais completos.

Que estas linhas singelas sirvam como homenagem á sua pranteada memoria, e que a sua obra encontre continuadores de sua tempera.

J. I. L.

\title{
A LEISHMANIA NO CÃO
}

Quando a morte brutalmente o colheu, enchendo a Faculdade de uma grande dôr, misturada de surpresa, o Prof. Pedroso andava em estudos, carinhosamente conduzidos, sobre a Leishmania tropical, a Meningite cerebro=espinhal e outras molestias ígadas á sua especialidade. A' meningite attribuem muitos dos selis amigos o contagio que o victimou tão cedo e inesperadamente; de experiencias sobre a Leis= hmania em cães tratou elle em varias secções da Sociedade de Biologia, desta Capital; é de uma ordem do dia d'aquella Sociedade que extrahimos a communicação hoje inserta em rıossas paginas.

Kevivendo, assim, o nome do saudoso professor de Microbiologia, entendemos manter vivo o nosso culto á memoria querida dos nossos mortos.

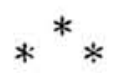


Eis o trabaiho do Prof. Pedroso:

\section{Injecção do cão pela Leishmania Tropical \\ PELO}

\section{DR. AlexandRino M. PEDROZO}

Director do Laboratorio anotomo=pathologico da "Santa Casa" de São Paulo..

e Prof. de Microbiologia da "Faculdade de Medicina e Cirurgica".

Por uma communicação feita, ha alguns annos, á Sociedade de Medicina e Cirurgica de S. Paulo, tivemos a opportunidade de descrever os dois primeiros casos de Leis= hmaniose tegumentar ou local, affectando expontaneamente os cães e que têm sido mortos na zona servida pela estrada de ferro "Noroeste do Brasil"

Em 1913, durante uma viagem que fizemos com c Professor Brupt, na mesma região, pudemos fazer vir um desses cães já descriptos por um de nós (Pedroso), em nossa primeira communicação, e dois outros, um cão e uma cadella, que descobrimos no kilometro 336 da mesma estrada de ferro.

Destes tres animaes, os dois machos morreram algum tempo após a sua chegada; tivemos, entretanto, o tempo sufficiente para fazer os exames, e constatar a Lesishmania, em "frotis" das ulcerações.

No que veiu do kilometro 336 , achamos uma ulceração sobre a parte externa do bordo direito do nariz, quasi completamente cicatrisada, donde pudemos retirar o material apropriado para a cultura.

Destes quatro animaes, um só, a femea, sobreviveu á infecção; ella mesma morreu cinco annos mais tarde, durante a epedimia de grippe, em 1918, que foi egualmente fa. tal para muitos doentes portadores da infecção leishmaniotica nasopharnigéa.

Esta cadella do kiiometro 336, logo depois que chegou a S. Paulo, muitas melhoras experimentou em seu estado geral, e, alguns mezes depois, apresentava ulcerações nasaes, em via de restauração, demonstrando, entretanto, alguns pequenos pontos indolentes do lado esquerdo do nariz, que, ás vezes, cicatrisavam, para se tornarem ulcerados algum tempo depois; não tendo sido possivel, nos ultimos tem- 
pos, demonstrar a presença da Leismmania, em "frottis" do tecido tirado desta parte.

Temos, portanto, o' total de 4 casos de Leishmaniose expontanea do cäo, verificados microscopicamente, e de um destes casos com cultura; 3 destes cães sucumbiram em consequencia da molestia, dando uma mortalidade de 75 olo.

Em todos estes casos, as lesões se localisam no nariz, não tendo sido observada outra localisação.

Alguns anıos depois de nossa communicação, YAKIMEFF e SCHEKHOR, verificaram, na Asia, a existencia da toença em um cão, tendo sido os primeiros a observar a forma puramente cutanea da affecção nestes animaes.

Taes são, em summa, os casos de Leishmaniose tegu= mentar, verificados no cão.

Passando, agora, á parte experimental da doença, vemos que quando se reproduz no cão, ella se mostra sempre extremamente benigna, pois que, de varios casos descriptos por NICOLLE e MANCEAUX, nenhum teve terminação fatal, nem houve necessidade de mais de tres mezes para a ctra completa.

Das inoculações feitas por NICOLLE eMANCEAUX, seja do homem ao cão, ou de cão a cão, nunca a doença teve evolução semelhante áquella observada na maioria dos casos de affecção humana.

Em nenhum de seus casos, absolutamente, elles pude:am observar a formação das ulceras.

Muitos outros investigadores. como NICOLLE eMAN= CEAUX, reproduziram a doença no cão, e todos, com resultados mais ou menos identicos.

Assim, dos cãos nioculados por LAVERAN, com Leis= hmania tropical, varios dentre elles tiveram nodulos que soffreram punção para fins diagnosticos; é difficil de saber si as ulcerações, posteriormente desenvolvidos, tinham sido ou não consequencia das puncções...

Entre elles, entretanto, em cão de seis mezes as ulceTações se desenvclveram como consequencia da evolução natural da doença, notandc-se que a cicatrisação reapareceu rapidamente.

Nenhum destes casos de LAVERAN teve um foim fatal, demonstrandu, ao contrario, uma grande benignidade.

Esta grande disparidade existente na lethalidade das duas formas da doença, tanto como a differença observada no aspecto anatomopathologico da lesão, me incitaram a reproduzir, embora de uma maneira não muito completa, como 
fizeram NICOLLE e MANCEAUX, n'uma de suas experiencias, empregando, para isso não sómente o "virus" e as culturas dos casos humanos observados em S. Paulo, como tambem as culturas da doença observada expontaneamente no cão.

Pára nosso material temos escolhido do serviço do Dr. Lindenberg, dois casos de Leismmania, um dos quaes apresenta sómente lesões cutaneas, e o outro já com manifestações mucosas.

As culturas empregadas foram obtidas, uma dum dos cães que fizemos vir do kilometro 336, e o outro, dum doente da clinica do Dr. Lindenberg.

Empregámos systematicamente a inoculação intradermica na região nasal desprovida de pelle, procurando sempre a que a agulha atravessasse uma extensão da parte epithelial do couro.

As culturas tinham sempre de 8 a 15 dias, e nunca conseguimos inocular uma grande quantidade de liquido, apezar da pressão exercida sobre o embolo da seringa.

$\mathrm{Na}$ verificação dos resultados, não temos tomado muito em conta a data $\mathrm{d} \backsim$ apparecimento das lesões, pois que, não é facil de apreciar no nariz do cão o momento em que o nodulo começa aparecer, bem como o momento em que a cicatrisação se completa.

Antes, pois, de começar nossos estudos, tomamos quatro cãesinhos, de menos de dois mezes de idade e fizemos a inoculação intradermica, examinando-os ao menos duas vezes por semana, sem ter até um mez depois, verificado alguma alteração tio ponto da inoculação. Depois de tres semanas, após a ultima inspeç̧ão, verificamos, com surpresa, que todos os quatro cãcs apresentavam pequenas ulcerações no nariz, ulceraçües que augmentavam progressivamente até que mais da metade da aza nasal ficou tomada tendo, então, o aspecto das ulcerções typicas verificados no homem.

No sexto mez as ulcerações estavam aparentemente c1catrisadas.

A curiosidade, no caso, é a rapidez da evolução dos nodulos para a ulceração, depois de um periodo latente, relativamente longo.

O primeiro resultado era igualmente em completo desaccordo com o obtido pelos investigadores que tinham estıdado a questão até então, pois que as lesões obtidas por elles, não eram semelhantes áquellas observados por nós, nem sómente á que produzıa na apparencia a etxensão e se- 


\section{HOM ENAGE;M}

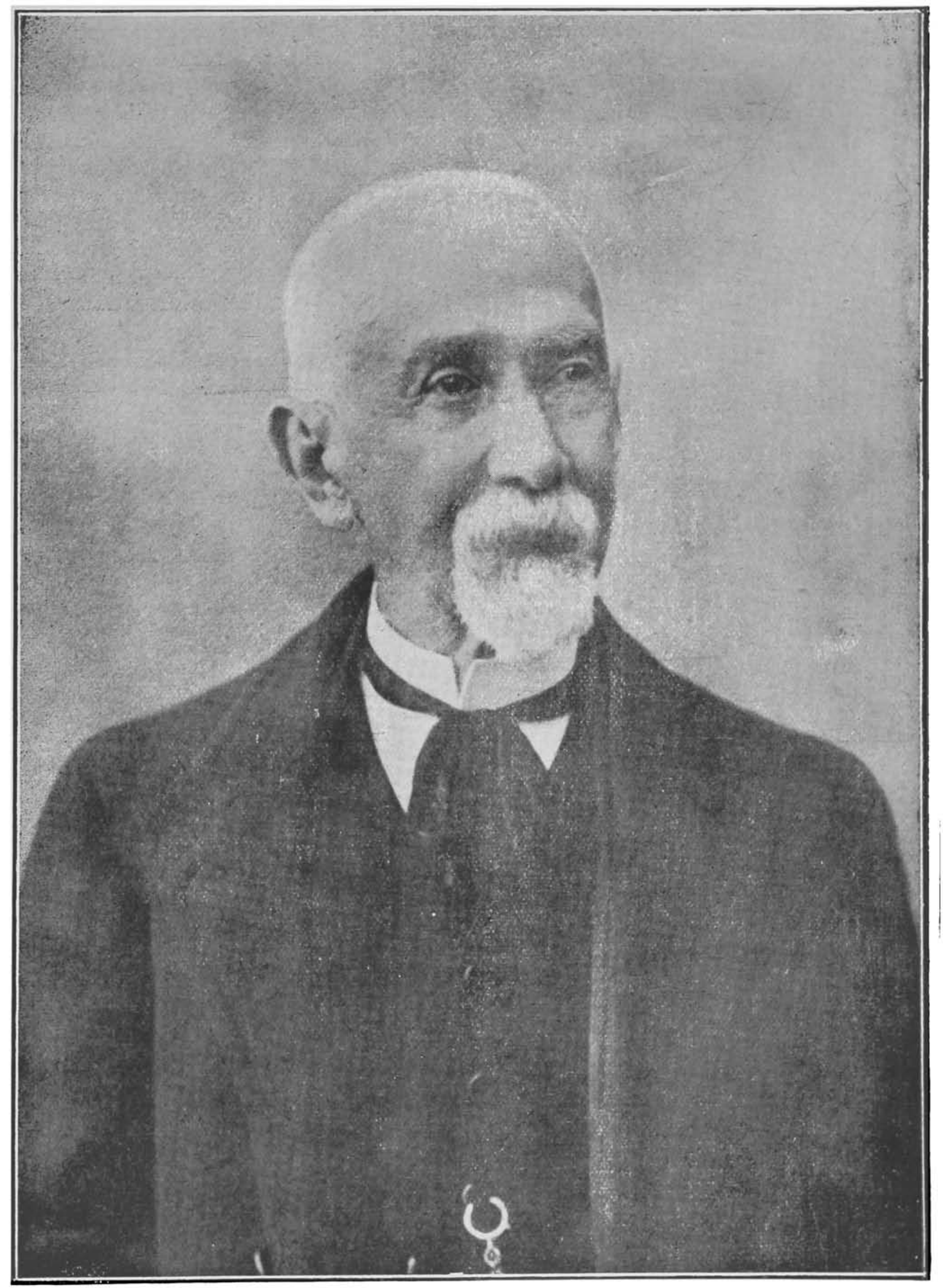

DR. LUIZ PEREIRA BARRETO, Mestre de nós todos e sabio entre os Mestres, 1 "Revista de Medicina" 

veridade da lesão, como tambem no tempo necessario para a cura completa dos animaes.

Alguns scientistas, tendo por base a marcha clinica, a cronicidade das lesões e a porcentagem das localisações nas mucosas affirmam que :s nossa Leismmaniose é differente da Oriental.

(Continua)

\section{LUIZ PEREIRA BARRETTO \\ PELO \\ DR. EMILIO RIBAS}

A vida do dr. Luiz Pereira Barretto se resume sobretudo nas manifestações do seu talento, do seu patriotismo e bondade.

Além dos de ordem medica, os assumptos de alta revelancia social têm recebido sempre o influxo do seu saber e, no caso particular de S. Paulo, todos conhecem que elle tem voltado as suas vistas de scientista e observador emerito para os interessantes problemas agricolas e de pecuaria, procurando facilitar o desenvolvimento destes factores maximos da nossa riqueza.

Comprehendendo, porém, que o progresso, para ser completo, precisa de um povo forte e que habite em regiões salubres, o dr. Barretto vem prestando ha muitos annos o seu intelligente concurso para a solução de vitaes problemas de hygiene social.

E, si o seu talento tem triumphado por vezes em outros terrenos, năo são menos admiraveis os seus serviços em pról da salubridade do nosso paiz.

O typho americano, originario do Novo Mundo, teve os seus principaes fócos, desde época remota, no Golfo do Mexico, Antilhas e America Central, irradiando-se destes pontos, geographicamnete estrategicos; para fragellar os outros paizes das duas Americas.

Em consequencias de enormes devastações deste flagello, contam os historiadores que na trceira expedição de Colombo, á que adheriram os homens livres, pelo terror que inspirava a despovoadora peste, teve o governo hespanhol necessidade, por fim de fundar as primeiras colonias, de lançar mão dos condemnados, promettendo-lhes a liberdade. 